\title{
Effect of Proficiency in English Language on Academic Performance of Post Graduate Management Students of Marathwada Region (Maharashtra), India
}

\author{
Pardeep Kumar \\ MGM Institute of Management, Aurangabad (Maharashtra), India -431003
}

\begin{abstract}
Students in any non-Hindi speaking state learn three languages and for a vast majority of them, medium of instruction at school level is Hindi. Since the students study English as one of the subjects, their proficiency in English remains low. This is more applicable to rural and semi-urban areas. This affects their performance in higher classes and professional courses where the medium of instruction is English. This study is an attempt to find out the effect of low proficiency in English on academic performance in postgraduate management students of Marathwada region of Maharashtra who come from rural and semi-urban areas. The study concludes that proficiency in English language and academic performance in management programmes are directly related and therefore much focused approach is required to be adopted in order to raise the level of proficiency in English amongst students of rural and semi-urban areas.
\end{abstract}

Keywords: Academic Performance, Proficiency in English, Cognitive Skills,

\section{Introduction}

Students with 45-50 percent marks at graduation level and a non-zero score in Combined Entrance Test (MAH-CET) qualify for admission to postgraduate management programmes (Master of Business Administration (MBA) /Master in Management Sciences (MMS)) in university affiliated colleges/institutes in Maharashtra (India). Since availability of MBA/MMS seats exceeds the number of applicants, the students with lowest qualifying scores can also get admission. Medium of instruction in management programme is English but the Proficiency in English (PiE) is not a criterion for admission to management programmes. Based on the three language formula, the students of this region learn three languages in schools i.e. Mother tongue (Marathi), official/official or associate official language of the union (Hindi) and a modern Indian language or a foreign language (English). Education at school level is imparted in one of these languages.

A vast majority of the students in this region are taught in their mother tongue up to middle school and they gradually keep shifting to English medium when they move to higher classes. Medium of instruction in management education at post graduation level is English only. The curriculum of management programme includes and is largely based on simple mathematics, statistics, social, bahavioural and management sciences. Academic performance in management programmes largely depends on reading, writing, analytical, application and verbal communication skills. Since the academic content is largely available and is delivered in English only, students with low PiE will find it difficult to cope up at graduation and post graduation levels. Since the students of Marathwada region come from rural and semi-urban schools and colleges with varying degrees of $\mathrm{PiE}$, it is interesting to study the effect of PiE on their academic performance.

\section{Objectives Of The Study}

The study attempts to establish a relationship between PiE and academic performance of post graduation (PG) management students of Marathwada Region of Maharashtra. The following hypothesis is to be tested:

Ho - Proficiency in English language has no significant effect on the academic performance of PG management students of Marathwada region (Maharashtra).

\subsection{Language Diversity and Teaching in India:}

\section{Review Of Literature}

Multilingualism is a symbol of diversity in India. Besides 22 languages recognized by Indian constitution in $8^{\text {th }}$ schedule, the Indian Census recorded 1576 rationalized languages as well as 1796 other mother tongues. 69-72 languages were taught in schools in India in some capacity and the number came down to 41 by 1993 .

Multilingualism confers definite cognitive advantages. Researchers have shown that there is a highly positive relationship between bilingualism/multilingualism, cognitive flexibility, and scholastic achievement (Peal and Lambert 1962; Gardner and Lambert 1972; Cummins and Swain 1986). Bilingual children not only 
have control over several different languages but they are also academically more creative and socially more tolerant (NCERT 2005).

Having recognized the importance of English as an instrument of knowledge dissemination, commerce as well as maintenance of international relations, a provision was left to extend the use of English language in the Article 343 as 'Official language of the Union'. Three language formula was adopted by AICE in Sept 1956 to teach three languages in first ten years of school education to strengthen the multilingual character of education system.

In India, 92.39 percent schools in rural areas and 90.39 percent schools is urban area teach through mother tongue. At the Upper Primary stage 91.34 per cent teach through mother tongue which consists of 92.71 per cent in rural areas and 87.37 per cent in urban areas. Percentage of students studying two or more mediums of instruction are 12.14, 14.47 and 18.53 in primary, upper primary and secondary stage respectively.

The students come across several difficulties belonging to pedagogic, curricular and environmental areas due to Three Language Formula (TLF). The most important ones, among them in order of descending difficulty, are, 'confusing to learn grammars of different languages' (pedagogic), 'no occasion to use the language for practice' (environmental), 'no extra coaching at home' (environmental), and 'many other subjects to learn' (curricular) (Subhash, 2013).

\subsection{Proficiency in English and Academic Performance}

Before proceeding it is important to define the two terms i.e. Proficiency in English (PiE) and Academic Performance. PiE can be defined as English language learners' communication information, ideas and concepts necessary for academic success whose first language is a language other than English and who is unable to perform ordinary classroom works in English (Driscoll, 2003).

Academic achievement is the outcome of education-the extent to which a student, teacher or institute has achieved their educational goals as reflected in the percentage of marks scored by the student in the university exam of any programme.

Problem of low academic performance in case of students with low PiE has been reported in literature through many studies conducted at school and graduation level in a member of countries. In USA, schools have focused so extensively on the task of learning English for those who are low in PiE that academic preparation and transition in to a new culture often fall by the wayside. In U.S. English learners (students with low PiE) are put in 'low track' classes and are considered to be low level learners. They are given instruction through lecture and paper pencil method. It has been shown that English learners perform poorly not because of their low proficiency in English but due to the method in which they are instructed. Such students find academics to be less challenging, less interesting and less engaging. Moreover, little is expected out of them and they become bored and their performance declines. The study concludes that it is not the language proficiency but the instruction and programme offering which outweigh language proficiency. It was further recommended that schools should provide rigorous academic curricular to English learners if they want them to succeed. (Rebecca M. Callahan, 2005). Primary language instruction was held forth as a way to prevent students from falling behind academically while learning English. With immigrants who enter US high schools with limited English proficiency, inconsistent prior schooling can be a barrier to success. High dropout rate among English learners may be symptomatic of the academic disconnect experienced by minority and linguistic minority students alike (Secada et. al. 1998). Some authors have advocated that students who enter schools with lower level of academic performance, need to be taught in simplified remedial manner allowing better prepared students to move unhampered by their slow classmates. At some schools, students who are considered weak in English are taught poorly considering that they are academically weak and consequently they become weaker in academics. These students are exposed to rate scripted language and repetitive information and they fail to develop analytical skills, questioning and argument (Harklau, 1994). In a study on the academic performance in school students in U.S., it was found that learning English is neither the sole nor primary determinant of academic performance of English learners. Availability of trained and prepared teachers also makes difference to improve academic performance.

English is not important but rather quality of English taught-academic English in particular-is critical and language instruction must be combined with strong content area curriculum development. English proficiency is necessary but schools fail in the type of English language being taught and rigors of academic preparation of students. English learners must not be termed as low level learners. At many schools, English language acquisition is emphasized at the expense of academic preparation and academic content is covered less vigorously (Minicucci \& Olsen, 1992, Olsen, 1995). Schools don't focus on English learners. They brand them as English learners and keep focusing on language than academics. Success of English must be complemented as English only is not important to ensure academic success. Long term English learners get in to a vicious circle of under preparation. They are denied access to challenging content area. 
Another study concluded that the IELTS scores show a little evidence for validity of IELTS as a predictor of academic success confirming previous research which suggested that language is but one of the many important contributing factors (Dooey and Oliver, 2000).

In another study carried out on business accountancy students, relationship between PiE measured by GPA in English and academic performance measured from GPA in final semester was conducted in a university in Somalia (Abdirahman M, Addow et. al. 2013). It was found that there are factors other than PiE that affect students academic performance. The result revealed than PiE has insignificant positive relation with their academic achievement and that there is an insignificant impact of English language proficiency on students' academic achievement.

In a study carried out in Tanzanian schools, student success in school was reported to be dependent on their proficiency in medium of instruction (Wilkinson \& Silliman, 2008). It was found that academic success is a function of several variables and not only proficiency in language of instruction. However, low academic performance was directed to proficiency in English (Tonkyen, 1995). Most universities in the world and Tanzania in particular require students to enter university with a basic level of competence in four distinct skills i.e. reading, speaking, writing and listening. This language proficiency is a critical determinant in predicting their success in the universities. Factors like human resource, infrastructure and learning material have also been blamed. In 1984, Cripper \& Dodd studied the problem to find that level of English proficiency among most Tanzanian students was so low that it hindered learning at alarming rate. Myungi and Osbiston argue that proficiency in language of instruction is an important factor in education performance and lack of proficiency in the same would result in poor performance in academics. Fakeye and Ogunsiji (2009) found that English language proficiency of students in Nigeria has a significant positive relationship with their overall academic achievements.

Job Wilson et. al., concluded that language plays a role but not a major and dominant role in academic success. In other studies in USA, Europe and West African countries researchers found a positive correlation (Bellingham, (1993), (1998), Fakeye and Ogunsiji (2009)) and weak correlation (Dooey \& Oliver, 2002) between $\mathrm{PiE}$ and academic performance.

Having difficulty in grasping fully the contents and concepts of various subjects of the curriculum taught in the target language (English) seems to be one of the most serious problems that the students face in their particular course of study (Zangani and Maleki, 2007).

Studies carried out to determine relationship between PiE and academic achievement by Wille (2006) for Hispanic students in USA and Shiraz University of Iran have found significant relationship between PiE and academic achievement. (Sahragard et. al. 2011).

In a study carried out in an engineering college in north India, it was found that there is no significant difference in the academic achievement in computer programming between English and Hindi medium students who were instructed through Hindi and English (opposite to their medium of instruction) video lectures (Yogendra Pal, Sridhar Iyer, 2012).

Students with low proficiency of English have problems pertaining to reading and writing ability. Most read at 174 words per min. with 62 percent understanding compared with 240 words per min. and $70 \%$ understanding.

\section{The Problem}

In the conundrum of variations and the conclusions of the studies, it becomes very interesting to explore the relationship between $\mathrm{PiE}$ and academic performance in the case of management graduates who come from rural and semi-urban areas of Marathwada region. Most of these students start their schooling in mother tongue and gradually change over to English. Changeover of the medium of instruction with advancement in levels is shown in Table 1 below.

Table 1: Medium of Instruction of PG students of Marathwada Region from $1^{\text {st }}$ class to PG in Percentage (n=170) (Mother Tongue (MT), English (Eng))

\begin{tabular}{|c|c|c|c|c|c|c|c|c|c|}
\hline \multicolumn{2}{|c|}{ Upto 8 $^{\text {th }}$ Class } & \multicolumn{2}{c|}{$\mathbf{0 9 - 1 0}$ Class } & \multicolumn{2}{c|}{$\mathbf{1 1 ~ \& ~ 1 2 ^ { \text { th } } \text { Class }}$} & \multicolumn{2}{c|}{ Graduation } & \multicolumn{2}{c|}{ PG } \\
\hline MT & Eng & MT & Eng & MT & Eng & MT & Eng & MT & Eng \\
\hline 66.5 & 33.5 & 64.2 & 35.8 & 27.1 & 72.9 & 11.2 & 88.8 & - & 100 \\
\hline
\end{tabular}

Only 35.8 percent students study in English medium till $10^{\text {th }}$ class but 72.9 percent study in English medium from $11^{\text {th }}$ class to graduation (for 5 years). It remains to be seen as to what level of PiE these students achieve and how the PiE affects academic performance in PG management education in case of students of Marathwada region. 


\subsection{Sampling and Sample Size}

\section{Methodology}

Students of MBA programme studying in a management institute at Aurangabad in Marathwada Region of Maharashtra were selected for the study. Marathwada region is composed six districts located in the hinterland of Maharashtra and is dominated by rural areas with a few semi-urban and still fewer city dwellings. The sample was taken from one institute only in order to eliminate the effect of other factors like quality of faculty, infrastructure and other independent variables. A total of 108 students were finally selected for the study.

\subsection{Data Collection}

The Proficiency in English was determined by a test and academic performance in university exam of three semester examinations in terms of total marks obtained was considered for analysis and study.

$\mathrm{PiE}$ was determined by conducting a three stage test in the first week of their joining the MBA programme in Aug 2012. In the first step, the students were shown six pictures, one after the other, and they were asked to write an imaginary story on each picture in 3 minutes (on the lines of Thematic Apperception Test). In stage two, the students were shown 60 words one after the other and were asked to write a sentence on each word. Each word was shown for 15 seconds. In stage three the students were given 30 situations and they were asked to write their solution in one/two lines to each situation in half a minute each. Data given in Table I was obtained separately in Mar 14.

Depending on their performance, the students were classified as 'Adequate', 'Borderlines' and 'Inadequate' in their $\mathrm{PiE}$ thus making three sample populations. It was found that 41.1 percent students were inadequate and 30.6 percent were borderlines in their PiE. Merely 28.3 percent were found to be having adequate $\mathrm{PiE}$ required for a post graduate management programme.

The marks of MBA $1^{\text {st }}, 2^{\text {nd }}$ and $3^{\text {rd }}$ semesters of university exams were obtained from university marksheets. The academic achievement and $\mathrm{PiE}$ of three sample populations i.e. adequate, borderlines and inadequate were compared. Thirty six students from each level of PiE were selected for study at random.

4.3 Data Analysis

Average marks of each sample population in all three semesters are given in the Table 2 below:

Table 2: Average Marks of all Three Populations in each Semester

\begin{tabular}{|l|c|c|c|}
\hline \multirow{2}{*}{ PiE of Population } & \multicolumn{3}{|c|}{ Average Marks } \\
\cline { 2 - 4 } & MBA 1st Semester & MBA 2nd Semester & MBA 3rd Semester \\
\hline Adequate & $63.25 \%$ & $61.88 \%$ & $62.13 \%$ \\
\hline Borderline & $59.13 \%$ & $59.79 \%$ & $59.38 \%$ \\
\hline Inadequate & $57.38 \%$ & $57.88 \%$ & $58.38 \%$ \\
\hline
\end{tabular}

The data is depicted graphically below.

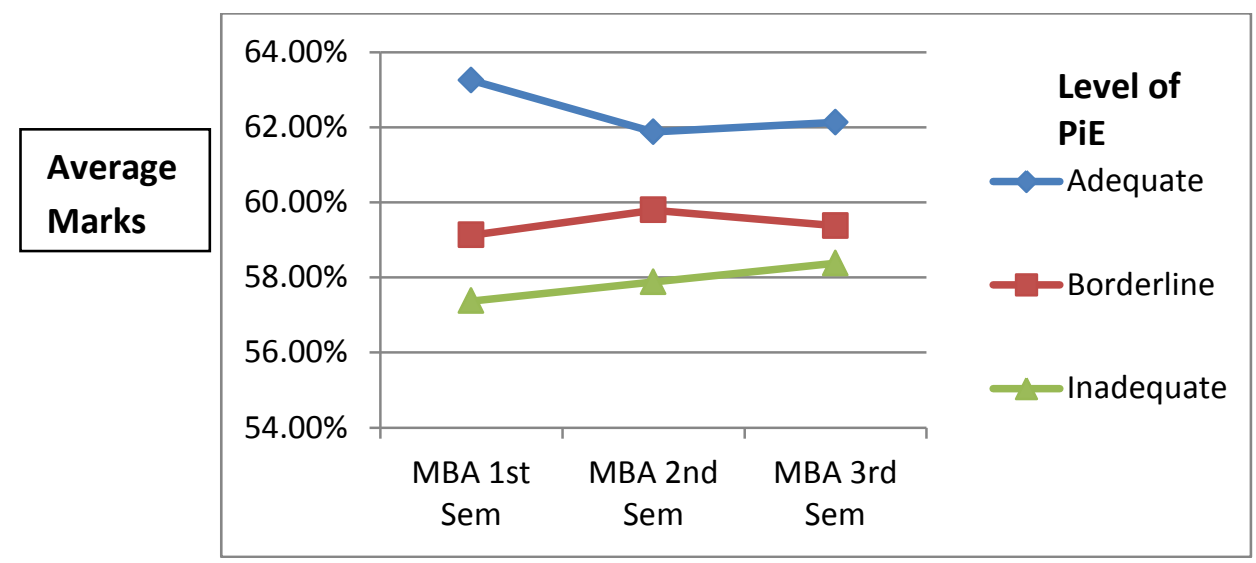

Fig I: Academic Performance of Three Populations of Students based on 3 levels of PiE in three Semester Exams.

Academic performance in three semesters of three samples of students possessing different $\mathrm{PiE}$ (Adequate, Borderlines and Inadequate) was compared statically. This was done to see if the difference in samples mean scores can be attributed to chance at 5 percent level of significance. Total sum of squares (TSS), treatment sum of squares (TrSS) and error sum of squares (SSE) of all three sample populations were calculated using the expressions as given below. 
Effect of Proficiency in English Language on Academic Performance of Post Graduate ....

TSS $=\sum_{\mathrm{i}=1}^{\mathrm{k}} \sum_{\mathrm{j}=1}^{\mathrm{n}} \mathrm{x}_{\mathrm{ij}}^{2}-\frac{1}{\mathrm{kn}} \cdot \mathrm{T}_{. .}^{2} \quad, \operatorname{TrSS}=\frac{1}{\mathrm{n}} \sum_{\mathrm{i}=1}^{\mathrm{k}} \mathrm{T}_{\mathrm{i} .}^{2}-\frac{1}{\mathrm{kn}} \cdot \mathrm{T}_{. .}^{2} \quad$ SSE $=$ TSS - TrSS

(Where, $X_{i j}=j^{\text {th }}$ observation of $i^{\text {th }}$ group, $T$.. $=$ Grand total of all scores, $K=3$ (No. of samples), $n=36$

(number of students in each sample), Ti. $=$ Total scores in each group.) Variation in their group is given by error sum of square (SSE) which is the difference between TSS and TrSS. The equality between TrSS and SSE for all three groups in three semesters is calculated in one way ANOVA Table 3 below:-

Table 3: One way ANOVA Table $(n=36)$

\begin{tabular}{|c|c|c|c|c|}
\hline Sources of Variation & Degrees of Freedom & $\begin{array}{c}\text { Sum of Squares of } \\
\text { Scores }\end{array}$ & Mean Square & $\begin{array}{c}\mathbf{F}_{105}^{2} \\
(\mathrm{MSTr} / \mathrm{MSE})\end{array}$ \\
\hline \multicolumn{5}{|c|}{ MBA I Semester } \\
\hline No. of samples & $(\mathrm{k}-1) \quad 2$ & 36155.13 & MSTr 18077.565 & 10.4853 \\
\hline Error & $\mathrm{k}(\mathrm{n}-1) 105$ & 181028.61 & MSE 1724.028 & \\
\hline Total & $\begin{array}{ll}\mathrm{kn}-1 & 107\end{array}$ & 217183.74 & & \\
\hline \multicolumn{5}{|c|}{ MBA II Semester } \\
\hline No. of samples & 2 & 19097.556 & MSTr 9548.7778 & 4.01434 \\
\hline Error & 105 & 241977.11 & MSE 2304.5439 & \\
\hline Total & 107 & 261074.67 & & \\
\hline \multicolumn{5}{|c|}{ MBA III Semester } \\
\hline No. of samples & 2 & 19845.574 & MSTr 9922.787 & 4.9635 \\
\hline Error & 105 & 209909.94 & MSE 1999.1423 & \\
\hline Total & 107 & 229755.52 & & \\
\hline
\end{tabular}

MSTr = Mean Square due to Treatment,

MSE = Mean Square due to Error

In the table it is clear that in all three semesters the computed value of $\mathrm{F}$ is greater than tabulated $\mathrm{F}$ value (which is 3.09 for $F$ with 2 degrees of freedom in numerator and 105 degrees of freedom in denominator) and hence null hypothesis is rejected in all three semesters. All three populations are different in their academic performance and the variation in marks is not a matter of chance. It means that the academic performance of PG management students is dependent on $\mathrm{PiE}$ at 5 percent level of significance.

\section{Discussion}

Rejection of Ho means that more proficient a student in English is, more likely she can score better in PG management education. It means that the curriculum content has been imbibed better by those who are proficient in English. Therefore PiE plays a major role in bettering academic performance.

The data also shows that though 72.9 percent students had studied in English medium from class $9^{\text {th }}$ to graduation level (for 5 years) yet only 28.3 percent students gained adequate PiE whereas 41.3 percent were still borderliners when they reached postgraduate level. Therefore it is concluded that studying in English medium did not improve their PiE even after reaching PG level. It is important to build strong foundation in teaching of English at school level for achieving better PiE. In the absence of adequate PiE, the academic performance and employability of the PG management students will suffer.

It can also be argued that standard of education and the implied decline in employability of students is due to the fact that the students are required to learn an alien language as brought out in a study in Tanzanian Schools (Mwansko, 1996). A recent study by ASSOCHAM found that employability of Indian B-School graduates is only 10 percent despite the demand. Similarly National Employability Report of MBA Graduates, 2012, puts employability figures between 10-20 percent with a remark that 32 percent management graduates lose out because of lack of English and Cognitive skills (Aspiring Minds, 2012). Changing over the medium of instruction to Hindi/any other local language as advocated by the supporters of local languages, would not be correct until and unless the academic content is not made available in local languages, the faculty is trained, curriculum is redesigned, student academic performance at foundation level is improved and infrastructure is overhauled.

Though English is becoming more ubiquitous in Indian Society yet the teaching of English in rural and semi urban parts of the Marathwada region has not been able to raise the proficiency of students. It has also been observed that students who are not proficient in English are not confident enough to take part in collaborative, participative and interactive learning processes.

\section{Limitations Of This Study}

In addition to the effect of PiE there are other factors affecting academic performance like previous schooling, educational background (science, commerce, arts, IT, engineering etc.) at graduation level etc. which may form the basis of further studies on the subject. 


\section{Recommendations}

a) $\mathrm{PiE}$ is one of the major factors affecting academic performance of management students coming from rural and semi-urban areas. In the era of globalization, the futuristic role which business organisations and management students are likely to perform underline the fact that need for PiE will remain important.

b) State should ensure highly focused approach towards teaching of English in schools to enhance language proficiency thereby improving academic performance and employability of PG passouts.

c) Performance of students has not improved significantly by studying in English medium from high school till completion of graduation. Therefore test of PiE must be carried out as a part of entrance exam for PG management programmes.

d) Students who need to enhance PiE must be given special coaching for improvement.

e) Political pressure to change the medium of instruction to Hindi/mother tongue will affect the academic performance of students in PG management studies. It will be prudent that management education is imparted in English in the fast globalizing environment.

f) English learners shouldn't be termed as low level learners. Their performance improves when they receive instructions in English. However their performance can be enhanced if PiE is improved by the way of special coaching in English as mentioned above.

\section{Conclusion}

Majority of students of Marathwada region studying management programmes study in their mother tongue up to middle and high school level. In spite of the fact that more than 72 percent study in English medium from class 10 to graduation, their proficiency in English remains low. They find it difficult to cope up in professional courses at PG level where the medium of instruction is English. Low proficiency in English affects their academic performance adversely. Management graduates are expected to work in international environment and importance of their being proficient in English cannot be over emphasized. Therefore it is important to ensure that concerted efforts are made to ensure that students aspiring to study management must meet the criteria of proficiency in English.

\section{References}

[1]. Peal, E and Lambert W. E. 1962. 'The Relation of Bilingualism to Intelligence. Physiological Monographs. 76.

[2]. Gardner R. C. and Lambert W. E. Attitudes and Motivation in Second Language Learning. Rowley Massachusetts. Newbury House Publishers. 1972.

[3]. Cummins and Swain. Bilingualism in Education. Longman London.1986.

[4]. NCERT. National Curriculum Framework - 2005. National Focus Group Position Paper on Teaching of English. New Delhi, India.

[5]. Subash. Three Language Education Formula in Multilingual India: Problems and Prospects. International J. Education Research. Vol. 1, Issue 4, 2013. pp. 150-158

[6]. Driscoll, D. P. English Language Proficiency Benchmarks and Outcomes for English Language Learners. The Commonwealth of Massachusetts, Department of Education. 2003.

[7]. Rebecca M. Callahan. English Language Proficiency and Track Placement: Variable Effects on Academic Achievement. p.429. Available at www.lingref.com/isb/4/033ISB4.PDF accessed on 08 July 2013.

[8]. Secada, W. G., Chavez-Chavez, R., Garcia, E. E. Munoz, C., Oakes, J., Santiago-Santiago, I., \& Slavin, R. No more excuses: The final report of the Hispanic Dropout Project. 1998.

[9]. Harklau, L. From the "good kids" to the "worst": Representations of English Learners across educational settings. TESOL Quarterly, 34(1). 2000. pp.35-67.

[10]. Minicucci, C., \& Olsen, L. Programs for Secondary limited English proficient students: A California study. Washington, DC: National Clearinghouse for Bilingual Education. 1992.

[11]. Dooey, P., \& Oliver, R. An investigation into the predictive validity of the IELTS test as an indicator of future academic success. 2002. Prospect, 1, pp.36-54.

[12]. Abdirahman M. Addow, Abdullahi Hussein Abubakar, Mohamed Said Abukar. English Language Proficiency and Academic Achievement for Undergraduate Students in Somalia. available at http://www.erint .savap.org.pk/pdf/vol.2(2)/Erint.2013(2.208).pdf, accessed on 28/ Feb,2014.

[13]. Wilkinson, L., Morrow, L., \& Chou, V. Improving literacy achievement in urban Schools: Critical Elements in Teacher Preparation. Newark: International Reading Association. 2008.

[14]. Tonkyn, A. English language proficiency standards for overseas students who need what level? Journal of International Education, 6, 37-61. 1995.

[15]. Criper ,C.,\& Dodd, W. Report on the teaching of English language and its use as a medium in Education. Dar es Salam. The British Council. As quoted in Job Wilson \& Sotco Claudius Komba, World Journal of English Language, The Link between English Proficiency and Academic Performance: A Pedagogical Perspective in Tanzanian Secondary Schools, World Journal of English Language, available at www.sciedu.ca/wjel.

[16]. Ogunsiji, Y. \& O, F. D. English Language Proficiency as a predictor of Academic Achievement among EFL students in Nigeria. European Journal of Scientific Research, 37(3), 490-495. 2009.

[17]. Job Wilson \& Sotco Claudius Komba. The Link between English Proficiency and Academic Performance: A Pedagogical Perspective in Tanzanian Secondary Schools. World Journal of English Language, available at www.sciedu.ca/wjel accessed 18 Jan, 2014,

[18]. Bellingham, L. The Relationship of language proficiency to academic success in international students. New Zealand Journal of Educational Studies. 30, pp. 229-232. 1993.

[19]. Fakeye and Ogunsiji Y. English language proficiency as a predictor of academic achievement among ELF students in Nigeria Journal of Science Research. 37. 2009 
[20]. Dooey, P., and Oliver,R. An investigation in to the predictive validity of IELTS test as an indicator of future academic success. Prospect, 1, pp. 36-54.

[21]. Zangani, E. \& Maleki, A., A Survey on the Relationship between English Language Proficiency and the Academic Achievement of Iranian EFL Students. Asian EFL Journal, 9(1). 2007.

[22]. Wille, J. R. Measuring the Academic Achievement and English Language Proficiency of Students at Secondary level. University of Wisconsin-Stout. 2006.

[23]. Sahragard, R., Baharloo, A. \& Ali, S. M. A Closer Look at the Relationship between Academic Achievement and Language Proficiency among Iranian EFL students. Theory and Practice in Language Studies, 1(12), 1740-1748. 2011.

[24]. Yogendra Pal, Sridhar Iyer. Comparison of English versus Hindi medium students for programming Abilities Acquired through video based Instruction, available at www.it.iitb.ac.in/sci/papers/programming-hindi-t4e2012.pdf on 05 May 2014.

[25]. Mwansoko, H. Kiswahili: Should it be used to teach at university? The Guardian March $2^{\text {nd }} 1996, \mathrm{p} 6$.

[26]. NationalEmployabilityreportofMBAGraduates2012availableatwww.aspiringminds.in/researchcell/articles/national_employability_r esearch_mba_graduates_2012.htmlaccessedon05May2014. 